\title{
DO “HOMO CONSUMERICUS” AO SER BIOÉTICO: A FUNÇÃO SOCIAL DOS CONTRATOS DE CONSUMO SOB O VIÉS DA PROTEÇÃO DO MEIO AMBIENTE
}

\author{
FROM "HOMO CONSUMERICUS" TO BEING BIOETHICAL: THE SOCIAL FUNCTION \\ OF CONSUMER CONTRACTS FROM THE PERSPECTIVE OF ENVIRONMENTAL \\ PROTECTION
}

Recebido: 10.03 .2020

Fábio Campelo Conrado de Holanda

Doutor em Ciência Política pela UFRGS. Professor

do Programa de Mestrado em Direito da Uni7.

Procurador Federal da AGU.

E-MAIL: fabiodeholanda@yahoo.com.br

LATTES: http://lattes.cnpq.br/6078803341806941

ORCID: http://orcid.org/0000-0001-5125-5933
Aprovado: 11.02.2020

\author{
Ana Virginia Porto de Freitas \\ Mestranda em Direito pelo Centro Universitário \\ 7 de Setembro. Advogada \\ E-MAIL: virginiaportoadv@gmail.com \\ LATTES: http:/ /lattes.cnpq.br/753786196276161 \\ ORCID: http:/ / orcid.org/0000-0002-4841-6510
}

\begin{abstract}
RESUMO: Discute-se de que forma o direito do consumidor à informação se relaciona com a proteção jurídica do meio ambiente. Busca-se demonstrar que a criação de uma cultura de consumo sustentável exige a afirmação ampla dos direitos à informação e à liberdade de escolha, como garantias instrumentais à sustentabilidade. Identifica-se que, sem liberdade e informação, o sujeito é mero consumidor passivo, consumista indiferente aos impactos do consumo no meio ambiente. A pesquisa tem natureza teórica, indutiva e qualitativa, a partir de revisão bibliográfica. Serão analisados conceitos da sociedade para o consumo, relacionando-os a formação de uma identidade consumista indiferente ao consumo sustentável. Por fim, se discutirá a necessidade de aperfeiçoamente de mecanismos jurídicos que resguardem direitos personalíssimos do consumidor com vistas à promoção de padrões consumeristas mais saudáveis e sustentáveis.
\end{abstract}

PALAVRAS-CHAVE: Sociedade do consumo. Sustentabilidade. Direito à informação. Obsolescência programada. Lavagem verde.

\begin{abstract}
This paper discusses how consumer's right to information is related to the legal protection of the environment. The aim of this study is to demonstrate that the creation of a sustainable consumer culture requires the affirmation of the right to information and freedom of choice as instrumental guarantees of the fundamental right to sustainable consumption. It is evident that without information the person is a mere passive consumer, a consumer who is indifferent to the impacts of consumption on the environment. This is a qualitative theoretical and inductive literature review. Concepts of consumer society will be analyzed, and they will be related to the formation of a consumer identity indifferent to sustainable consumption. Finally, the need to improve legal mechanisms to safeguard consumer rights to promote more sustainable consumption standards will be discussed.
\end{abstract}

KEYWORDS: Consumer society. Sustainability. Right to information. Scheduled obsolescence. Greenwashing.

SUMÁRIO: 1 Introdução 2 Liberdade, Identidade e Expectativa na Sociedade de Consumo 3 Estratégias de Mercado para o Consumo: O Problema da Informação face ao Estado de Direito 
Ambiental $4 \mathrm{O}$ Direito à Informação Ambiental enquanto Garantia de Efetividade do Direito Fundamental ao Consumo Sustentável 5 Conclusão 6 Notas de referência

\section{Introdução}

Algumas mudanças paradigmáticas advindas no universo das normas de direito privado no Brasil foram expressamente contempladas na Lei n.․ 8.078/90 (doravante nominada de Código de Defesa do Consumidor - CDC) e no Código Civil de 2002 (ambos em sintonia com o que já se observava em algumas legislações do direito comparado). A valorização do paradigma da socialidade na elaboração de seus textos e na interpretação das situações fáticas sujeitas às suas aplicações promoveu uma nova compreensão de institutos tipicamente privatistas como a propriedade, a posse, a empresa e os contratos, que foram paulatinamente se desconectando de um viés estritamente individualista (típico do Codex de 1916) para seguir um vetor alinhado às demandas da coletividade.

No microssistema normativo das relações consumeristas (cujo paralelismo nem sempre é observado no direito estrangeiro que, por vezes, regula tais situações negociais no próprio Código Civil), parte-se da premissa de que o destinatário final de bens e serviços é aprioristicamente considerado um vulnerável, dada a sua posição de inferioridade contratual sob o ponto de vista técnico e informacional, por exemplo.

Sendo assim, considerando que o estilo de vida pautado no consumismo (o sufixo "ismo" nesse caso é adequado por revelar excesso) altera a lógica do tempo de modo a encapsular a satisfação pelo consumo em instantes cada vez menores, ensejando a descartabilidade e a substituição rápida de bens de modo a causar perigos consideráveis não apenas à saúde física e mental do consumidor, mas à higidez do meio ambiente. Essa lógica é alimentada pela constante criação de necessidades na sociedade do consumo.

Assim, a obsolescência programada e o irrefletido descarte de resíduos sólidos se afiguram como problemas que servirão de ponto de partida para as reflexões que se pretende fazer no presente arrazoado, dada a necessidade de construção de um arcabouço teórico voltado à problemática ambiental e que seja apto a justificar práticas consumeristas mais éticas e preocupadas com os aspectos ecológicos, onde a expectativa de consumo de bens produzidos leve em consideração uma perspectiva sustentável.

Consumo e meio ambiente se vinculam na ordem jurídica por origens constitucionais, haja vista que o figurino constitucional federal traz a previsão da defesa do consumidor e da proteção do meio ambiente não apenas no rol de direitos fundamentais mas nas diretrizes de desenvolvimento da ordem econômica. Admitindo-se a recíproca afetação entre os subsistemas jurídicos, pretende-se refletir de que forma o direito do consumidor à informação se relaciona com a proteção jurídica do meio ambiente e confere efetividade ao direito fundamental ao consumo sustentável.

Pretende-se demonstrar que a criação de uma cultura de consumo sustentável passa necessariamente pelo resguardo de direitos do consumidor, tais como o direito à informação e a liberdade de escolha, como garantias instrumentais à sustentabilidade. Para tanto, adota-se aqui uma visão de que o direito se revela como resultado da construção cultural da sociedade, tendo em vista que a afirmação legislativa de direitos pode influenciar na mudança de modelos comportamentais, sobretudo na identificação, análise e reflexão dos temas bioéticos, bem como na característica do individualismo exacerbado da sociedade contemporânea, agudizada pela sociedade do risco. 
Desse modo, mostra-se relevante a discussão sobre a necessária previsão legal de ferramentas de informação ambiental ao consumidor, para que o ordenamento jurídico infraconstitucional seja instrumento de efetividade do direito fundamental ao consumo sustentável, por ser a proteção do meio ambiente de responsabilidade do Estado e da coletividade. As reflexões, de caráter dedutivo, utilizarão uma metodologia qualitativa, de cunho exploratório para a familiarização com o problema, a partir de revisão bibliográfica de literatura estrangeira e nacional. Será realizada, ainda, análise documental, adotando-se método explicativo, para identificar os fatores que contribuem para a ocorrência do fenômeno observado.

No primeiro tópico, serão analisados conceitos da sociedade para o consumo, trazidos por referenciais teóricos como, por exemplo, o sociólogo Zygmunt Bauman e Vittorio Hösle, relacionando-os à formação de uma identidade consumerista indiferente aos impactos do consumo no meio ambiente. No segundo tópico, se descreverão práticas utilizadas pelo mercado que interferem na liberdade de escolha do consumidor e induzem ao consumo insustentável, refletindo sobre tais práticas à luz do Estado de Direito Ambiental. Por fim, se discutirá o aperfeiçoamento de mecanismos jurídicos que disponibilizam uma maior autodeterminação do consumidor, com vistas à promoção de padrões consumeristas mais sustentáveis.

As críticas que o trabalho enfrentará serão suficientes contribuições para o avanço de tema tão caro para quem, como os autores, aqui revelam seu interesse por se imiscuir no estudo das relações consumeristas para além do que trazem os dispositivos normativos do CDC, em virtude das peculiaridades sociais de uma problemática que reclama um olhar multidisciplinar.

\section{Liberdade, Identidade e Expectativa na Sociedade de Consumo}

Nos processos de decisões individuais que adotamos diariamente em nossas práticas consumeristas há, indiscutivelmente, uma conexão entre instinto e racionalidade onde selecionamos aquilo que nos traz uma satisfação imediata. Tal processo é levado a cabo na grande maioria das vezes por conduto de uma análise econômica desconectada de um planejamento pós-contratual (momento em que o meio ambiente natural é impactado na maioria das vezes pelo descarte de resíduos sólidos, por exemplo).

A propósito de escolhas e dos reflexos ambientais respectivos, a economia comportamental e o estudo do cérebro podem trazer importantes elementos para o desenvolvimento teórico que ora se inicia.

Richard Thaler e Cass Sunstein são categóricos ao afirmar que o meio ambiente é resultado de um sistema global de arquitetura de escolhas em que as decisões são tomadas por todos os tipos de atores (consumidores ou fornecedores de bens e serviços e até o Estado). Segundo os autores, dois problemas se evidenciam na questão da poluição excessiva: o fato de que as pessoas não recebem um feedback das consequencias ambientais de suas ações e a circunstância dos incentivos não estarem devidamente alinhados, ou seja, se você adotar uma conduta danosa ao meio ambiente como consumidor, provavelmente não pagará nada pelos prejuízos que causará. ${ }^{1}$

Nas duas situações trazidas pelos autores, a liberdade do ato de consumir parece claudicar (sob um olhar voltado ao social) em face da insuficiência das informações relativas ao chamado consumo consciente. Características aparentemente insignificantes das relações sociais (no caso concreto, um maior esclarecimento nos contratos de consumo) podem exercer um impacto decisivo no comportamento das pessoas, alterando a arquitetura de suas escolhas.

Lúcidas as considerações de Ulrick Beck ao afirmar que a produção em massa, os avanços tecnológicos e os efeitos da globalização do mercado, gestados a partir da sociedade industrial, 
produziram riscos imprevisíveis que afetam todas as relações sociais, impondo graves consequências.

No contexto do consumo, o aumento da utilização de recursos naturais não renováveis para a elaboração de produtos que tem vida útil artificialmente encurtada (obsolescência programada), com a geração de grande contingente de resíduos sólidos não absorvíveis ou altamente tóxicos, incrementa a degradação ambiental. Observando-se os riscos ambientais gerados pelo consumo, pontua o autor que "sua invisibilidade não deixa nem mesmo uma decisão aberta ao consumidor." ${ }^{2}$

Para além da festejada transição entre a modernidade sólida (sociedade de produtores) e a modernidade líquida (sociedade de consumidores), proposta por Bauman, o que se viu foi a eclosão de fenômenos que desconstroem as noções e as instituições que davam estabilidade à vida pública ${ }^{3}$.

Para a compreensão da sociedade do consumo, Bauman indica três elementos essenciais à sua configuração e análise: o primeiro elemento é o consumismo (uma revolução consumista, quando se altera do qualitativo para o quantitativo, a partir da mudança das formas e das quantidades de acumulação de bens), concebido a partir de uma relação extrema o consumo, o segundo é constituído pelas dinâmicas que envolvem a implementação do consumismo na sociedade de consumo e o terceiro é uma conseqüência dos dois anteriores: o estabelecimento de uma cultura de consumo ${ }^{4}$.

No âmbito jurídico, ampliou-se a concepção sobre a relação privada de consumo, abandonando-se o modelo linear e mecanicista, que reduzia o aspecto relacional aos sujeitos consumidor-fornecedor, para a adoção do modelo helicoidal e complexo, no qual se incluem aspectos multidimensionais, internalizando-se as pressões derivadas do consumo no ecossistema ${ }^{5}$. Considerar, portanto, que a relação de consumo alberga externalidades que vão além da dinâmica do fato juridico (o contrato) é providência que se impõe.

Assim, o consumo passa a orbitar na centralidade da vida social quando seu objetivo deixa de ser uma necessidade existencial ou imanente para transformar-se em uma necessidade construída e habitual, forjando-se expectativas e desejos, individualizando o sujeito e impedindo a percepção dos impactos desse movimento consumista sobre o meio ambiente.

Para ser um atributo da sociedade, o consumismo substituiu o valor mais precioso da sociedade de produtores: o trabalho. Este define a identidade do individuo na comunidade a partir da ocupação e da função social. O consumo passa a ser objeto de uma frequente expectativa, uma promessa da felicidade que, segundo o pensamento de Gilles Lipovetsky, se traduz em "um complexo de mitos, de sonhos, de significações imaginárias que, impulsionando objetivos e confiança no futuro, favorece a reoxigenação de um presente muitas vezes esgotado." 6

Na sociedade do consumo, altera-se a lógica mental do indivíduo para lhe fazer crer que o trabalho se coloca em função do ato de consumir (quando, em verdade, a motivação do trabalho encontra raízes existenciais dirigidas à conquista de sua dignidade). A liquidez dos tempos modernos fomenta a instabilidade de desejos e a insaciabilidade das necessidades. Uma vez capturado pela dinâmica da sociedade de consumo, o homem passa a modular sua identidade através do possuir. A aquisição de bens e serviços se confunde com sua ontologia já que se vive para o consumo.

Ainda nos valendo do pensamento de Bauman, o consumismo se apresenta como um eficaz fator de integração, de estratificação e de identificação do indivíduo, principalmente porque adquire um papel preponderante nos processos de auto-referência das pessoas e dos grupos $^{7}$. Retirando do indivíduo a noção de pertencimento na natureza, o consumismo cria constantemente uma realidade artificial, ao vincular o consumo com a ideia de progresso. Nesse 
contexto, o direito do consumidor, desenhado pelo modelo consumidor-fornecedor, mostra-se muito conveniente para servir como "ferramenta de estímulo ao consumo". ${ }^{8}$

Essa sociedade do consumo, segundo Debord, chega ao seu auge consolidando-se como a sociedade do espetáculo, formulada pela glorificação da imagem, da aparência e da exibição. Seu valor encontra-se na ostentação do consumo, de tal sorte que a "alienação do ser toma o lugar do próprio ser. A aparência se impõe por cima da existência. Parecer é mais importante do que ser". 9

Em se tornando mercadoria através de consutas irrefletidas, o sujeito involuntariamente celebra o individualismo, alijando-se das necessidades sociais de equilíbrio dos finitos recursos naturais. Já que no momento em que resta suprimida uma necessidade, outra necessidade surge, a temporalidade naturaliza a brevidade do $\operatorname{produto}^{10} \mathrm{e}$, assim, desconectado do coletivo e dissociado de sua responsabilidade social, o consumidor não identifica riscos e consequências decorrente seus atos consumistas.

Pois bem, é aqui que se insere o diálogo central do presente artigo acerca da função social da relação de consumo, que a despeito de ter seu clímax na fase de execução contratual, reclama a atenção da sociedade acerca dos flagrantes reflexos que irradia na fase pós-contratual. Sendo assim, a regulação normativa das relações de consumo feita pelo Estado não deve servir de respaldo para ratificar a identidade do indivíduo como consumidor (entendido este como um sujeito alheio às externalidades que orbitam a "lógica do ter").

Essa sociedade do consumo, para manter sua reprodução e sobrevivência, desenvolve a cultura do consumo, que segundo Bauman, possuem dois pressupostos que asseguram o indivíduo na sociedade de consumo: a liberdade de escolha e a liberdade de descartar os indesejados. A liberdade, que tem sido um conceito filosófico central durante a história humana, é delimitada, na modernidade líquida, como liberdade para escolher e consumir ${ }^{11}$.

Atento à aderência do conceito de liberdade em relação ao fenômeno consumerista, Harvey pontua que a liberdade e o tempo são duas categorias concorrentes na lógica do consumismo. A liberdade de escolha será diretamente proporcional à urgência a decidir. A cultura consumista sugere viver com intensidade, no uso máximo dos potenciais do momento. Nisso reside o fundamento da legítima expectativa do consumidor: usufruir ao máximo e descartar para voltar a consumir. Esta é uma característica própria da condição pós-moderna ${ }^{12}$.

A descartabilidade é uma característica desses tempos ligeiros, imiscuindo-se não apenas nas relações do homem com as mercadorias, mas no trato social em geral, com reflexo na família, nas relações profissionais etc. Na sociedade consumista, a liberdade de eleger e descartar se estende a todos os âmbitos da vida social. A construção da identidade do sujeito e o exercício da liberdade individual na modernidade líquida passam por uma conformação a partir da cultura consumista. Nesse contexto, a sociedade do consumo produziu o consumidor passivo, sujeitoobjeto no ato de consumir, balizado pelo movimento do mercado e indiferente aos impactos de seus atos no meio ambiente.

A propósito da forma individualista com que o homem se relaciona com o meio ambiente, Hans Jonas faz considerações de índole bioética que servirão de lastro para a teorização que se pretende consolidar acerca da função social do contrato de consumo, notadamente ao pontuar o seguinte:

Esse foi o ponto de vista prático de todos os tempos, ao longo dos quais o conjunto da natureza parecia invulnerável, estando, portanto, inteiramente disponível para os homens, como objeto de usos particulares. Mas se o dever em relação ao homem se apresenta como prioritário, ele deve incluir o dever em relação à natureza, como condição de sua própria continuidade e como um dos elementos da sua própria integridade existencial. 
Na esteira do pensamento de Vittorio Hösle (influenciado que foi por Hans Jonas), merece críticas a cultura ocidental que fomenta o consumismo exacerbado, olvidando da necessidade de pensar a ética para as gerações futuras. Segundo o referido autor, um dos objetivos da ética atualmente (no século do meio ambiente) seria promover uma mudança paradigmática não apenas racional, mas sentimental, na medida em que o mundo e as pessoas deveriam sentir novamente a beleza da natureza, observando o mal moral que os danos ao meio ambiente podem gerar através de uma crítica racional ao capitalismo. ${ }^{13}$

Em uma sociedade onde o indivíduo vincula o significado de dignidade ao seu correspondente poder de comprar, o desafio na ressignificação das práticas consumeristas para uma perspectiva mais consciente e ecologicamente responsável impõe a reafirmação de um substrato axiológico mais humanizado do consumidor ${ }^{14}$. No próximo tópico da pesquisa, as estratégias utilizadas pelo mercado de consumo servirão de didático manancial teórico a fim de identificar os intrumentos para a pretendida ressignificação do indivíduo no trato das relações de consumo.

\section{Estratégias de Mercado para o Consumo: O Problema da Informação face ao Estado de Direito Ambiental}

A Lei 12.305/10 quando foi editada representou uma inovação no ordenamento jurídico brasileiro, na medida em que apresentava, de forma didática, conceitos aplicáveis à matéria dos resíduos sólidos, prevendo uma atuação sistêmica da sociedade em aspectos ambientais, sociais, culturais, econômicos, tecnológicos e de saúde pública. A partir de então, passou a se valorizar o ciclo de vida do produto, contemplando o conceito de macrorrelação ambiental de consumo. ${ }^{15}$

O sistema de logística reversa proposto pelo microssistema das relações de consumo visa incluir os agentes econômicos na responsabilidade por embalagens e produtos utilizados transitando por rios e esgotos, compartilhando seu protagonismo da proteção do meio ambiente juntamente com o consumidor. Assim, o Estado de Direito Ambiental surge com a incorporação de novos valores, fulcrados não apenas no Estado Democrático de Direito, mas no Estado Social de Direito (ou do bem-estar social), que tem na sustentabilidade um de seus princípios estruturantes (e que fora introduzido no direito brasileiro por meio da Lei 6.803/1980) e que serve de paradigma no combate à chamada "obsolescência programada".

A propósito, segundo Latouche, a obsolescência programa consiste em um dos fenômenos que materializam a redução da liberdade do consumidor e o consequente incremento de sua vulnerabilidade perante o mercado, além de gerar impactos danosos ao meio ambiente, tendo em vista a frequente criação de resíduos. Estratégia de produção que reduz a vida dos produtos de consumo, a obsolescência planejada remonta a segunda década do século passado.

Pensada para dinamizar e estimular o consumo, conjuntamente com a publicidade e a abertura do crédito para o consumo, integrou a tríade que permitiu o auge da denominada sociedade do consumo. Fenômeno que promove a renovação constante de produtos duráveis e contribui para a perpetuação dos padrões de descartabilidade ${ }^{16}$.

Tratando do tema da obsolescência programada e seus reflexos nas relações de consumo, Holanda (2018) pontua que se deve analisar o desenvolvimento econômico não apenas sob o viés do crescimento da renda ou do número de consumidores, mas também entender no seu aspecto qualitativo, considerando a qualidade do produto e de vida do consumidor. ${ }^{17}$

Latouche ainda faz referência a três tipos de obsolescência: a técnica, a psicológica ou simbólica (faz referência ao uso e desuso provocado, não pelo desgaste técnico ou pela introdução de uma inovação real, senão pela desqualificação artificial do produto, pela criação de um novo desenho, estilo ou uma nova embalagem) e a programada. A obsolescência técnica 
implica no uso de máquinas e aparatos no processo produtivo, introduzindo inovações de todo tipo. A inovação torna-se aliada ao apelo do discurso político pelo desenvolvimento econômico, social e científico. A teconologia seduz o consumidor pela promessa de comodismo, rapidez e eficiência. ${ }^{18}$

Essa estratégia se viabiliza pela vulnerabilidade informacional do consumidor. incrementando-a, ao mesmo tempo, por submeter o consumidor a uma condição contratual. Com efeito, com o planejamento da usabilidade do produto baseado na assimetria informacional, é o fornecedor quem impõe ao consumidor os termos da relação de consumo.

Para o eficaz funcionamento do motor consumerista, o ato de consumir deve ser instantâneo, pelo que é necessária uma rápida eliminação, de fato e de desejo, dos objetos consumidos. De tal sorte que essa prática manipula a boa-fé e a confiança do consumidor, frustrando suas expectativas e lhe impondo a adesão a uma nova relação de consumo.

A obsolescência instrumentaliza, portanto, a crise da confiança entre fornecedor e consumidor, na medidade em que reduz a autodeterminação do consumidor por impor uma imprestabilidade precoce ao produto $^{19}$ alterando suas expectativas e the induzindo ao consumo poluidor e insustentável.

Com efeito, descartar o produto obsoleto indica a geração de resíduos para eliminação no meio ambiente. Esse processo de produção e descarte que vem comprometendo sobremaneira a higidez da natureza, especialmente com a utilização de materiais tóxicos na produção e com o crescimento de resíduos não orgânicos.

No âmbito do direito comparado, Pablo Lorenzetti destaca a preocupação com o consumo sustentável, contrapondo ao princípio "in dubio pro consumidor" o valor "in dubio pro natura". Segundo o autor, a jurisprudência argentina é enfática ao pontuar que o direito de propriedade encontra limites na tutela ambiental "ya que no es sustentable la permanencia de un modelo dominial que no lo tenga en cuenta. También el consumo debe ser adecuado a paradigmas sustentables en materia ambiental." ${ }^{20}$

Sobre a singularidade de seu imperativo categórico-tecnológico, Hans Jonas (arauto da chamada bioética ${ }^{21}$ ) pensa que manter a humanidade "incólume a través de los peligros de los tiempos, más aún, frente al propio obrar del hombre, no es una meta utópica, pero tampoco es en absoluto una meta modesta de la responsabilidad por el futuro de los hombres". ${ }^{22}$

Com lastro no pensamento de Vittorio Hösle, "o que precisamos não é a destruição da ciência e, com isso, no fim, também da razão, mas sim da transformação da ciência. A ciência deve se tornar mais holística, ela não deve reduzir seu tema a apenas um objeto". Ainda segundo o autor, ao tratar da distante relação entre a noção de progresso econômico e ecologia, "a emancipação do econômico em relação à coerção de normas de outros sistemas sociais como a família e o Estado é uma das mais profundas marcas distintivas da história europeia desde a revolução industrial, sendo isto uma das causas da crise ecológica". ${ }^{23}$

Didático esclarecer que bioética é o estudo sistemático e transdisciplinar do comportamento humano incidente na biotecnologia e em seus reflexos no cotidiano, que tem como escopo elevar ao clímax a dignidade da pessoa humana, partindo de uma visão integralizadora desta (pessoa humana), por meio do respeito a uma sistematização ética da responsabilidade e da elaboração de princípios universais e autônomos.

A questão da proteção ao meio ambiente veiculada no presente arrazoado e o aspecto social dos contratos de consumo se vinculam, em nosso sentir, aos conceitos da bioética, na medida em que o eixo central da bioética é o ser humano, a pessoa humana em sua integralidade, do início ao fim de sua existência, bem como o habitat que contribui para tanto.

Preocupado com a vulnerabilidade da natureza e da humanidade perante os avanços técnico-científicos, Hans Jonas elabora seu imperativo categórico-tecnológico direcionado para o 
comportamento social público, em face da parcialidade da autonomia do indivíduo, enquanto os imperativos categóricos de Immanuel Kant são direcionados ao comportamento social individual.

Ainda sobre o pensamento de Vittorio Hösle, interessante se apresenta uma reflexão acerca da compatibilização da economia com a ecologia (cujo principal ponto de conciliação residiria no negociar econômico para a obtenção de lucros com o mínimo de gastos o possível), notadamente acerca do comportamento egoísta e a eleição de qual seria o melhor sistema político-econômico para preservar o desenvolvimento aliado à proteção das questões ambientais:

Em primeiro lugar, é impossível eliminar o egoísmo; não se deve buscar o impossível, pois isso detém que se alcancem coisas efetivamente importantes; devemos proceder de forma econômica com as próprias energias, uma vez que elas são limitadas. De fato, a figura de Dom Quixote, para além de todo o aspecto risível, certamente possui algo sublime, pois ele lembra de que ideiais sempre transcendem a efetividade, sem a qual, portanto, sua validade como ideias reguladoras se perde; (...) Mas se nem a economia capitalista presente, nem a economia socialista podem represar a destruição ambiental em uma medida moralmente adequada, qual forma de economia é exigida, para se alcançar essa meta? Parece-nos que o único caminho praticável consiste na ideia de uma economia de mercado socialecológica. (...) Com consciência ecológica elevada na população, além disso, também o consumidor preferirá produtos que ele sabe serem compatíveis com o meio ambiente. ${ }^{24}$

De fato, o direito fundamental à informação, transportado para a órbita consumerista através da retórica da conscientização do consumidor, parece ser a chave para a virada paradigmática em relação à travessia do "homo consumericus" para o ser bioético. Quanto mais esclarecido acerca das fases que antecedem e sucedem a relação contratual, mais o destinatário final de bens e serviços terá a dimensão de seu protagonismo no processo econômico em que está imiscuido.

Com relação ao tema das relações consumeristas, verifica-se que a publicidade induz o consumidor a desejar bens para o consumo e a desprezar os que se tem para consumir outros, criando e recriando insatisfações e frustrações, sendo, além de provomer simbolicamente a descartabilidade, verdadeira técnica de promoção da obsolescência programada, por gerar a conformação do consumidor. Segundo Debord, na sociedade do espetáculo, "o princípio do fetichismo da mercadoria, a dominação da sociedade por "coisas supra-sensíveis embora sensíveis", se realiza completamente no espetáculo, no qual o mundo sensível é substituído por uma seleção de imagens" ${ }^{25}$.

Se de um lado, o avanço tecnológico atribui aos objetos a pecha de antiquados, de outro, a publicidade gera a "sensação de escassez" ${ }^{26}$, de modo que consumir passa a ser indicativo de prosperidade (orientado o consumidor sob o mantra de que "quanto mais atual é um produto, maior a valoração social dele" ${ }^{27}$ ). Assim, a publicidade cria valores e realidades, ao "ativar a imaginação dos consumidores, exagerando qualidades do produto" ${ }^{28}$ (em que pese não se permitir enquadrá-la como enganosa, nos termos do artigo 37, do CDC).

Outra tática mercadológica que enubla o direito de escolha do consumidor consiste na prática denominada greenwashing (lavagem verde), que distorce informações dadas ao consumidor sobre questões ambientais, sendo estratégia de explícita má-fé. A questão ambiental desencadeou um nicho de mercado destinado aos consumidores que demandam produtos sustentáveis. Empresas passaram a desenvolver marcas, denominadas ecomarcas ou marcas 
sustentáveis, que cultivam um conceito ecológico atraindo um segmento crescente de consumidores com consciência ambiental. ${ }^{29}$

O greenwashing, aliás, consiste na falsa indicação de sustentabilidade do produto, ou por ser inverídica a fonte do produto, ou por adulterar a descrição da forma de produção, ou por descrever patrocínio ecológico inexistente, dentre outras formas, desvirtuando a ideia essencial das ecomarcas. Trata-se de prática enganosa e afrontosa ao princípio da transparência e da boafé, por induzir ao consumo de produto que supostamente teria atratividade por atender às demandas de sustentabilidade. ${ }^{30}$

Cotejando-se essas práticas adotadas pelo mercado para fomentar e estimular o consumo, identifica-se um elemento comum e essencial que thes caracteriza: a manipulação da informação sobre aspectos fundamentais do produto ou serviço.

Quanto mais susceptível a tais estratégias do mercado dentro de seu âmbito personalíssimo, mais vulnerável se torna o consumidor pois, "vulnerabilidade é um conceito relativo, e, como tal, sua avaliação sempre dependerá do sujeito a ser considerado e da situação concreta em que ele se encontrar" ${ }^{\prime 31}$. Acerca desse conceito basilar das relações de consumo, tem-se que o grau de vulnerabilidade do consumidor mostra-se diretamente proporcional ao nível de informação que ele detém para realizar de modo livre e consciente o ato de consumir, já que "a informação é fundamental para o livre exercício da vontade na escolha pelo consumidor, superando os impulsos consumistas induzidos pelo mercado." ${ }^{32}$

Uma das diretrizes da política nacional das relações de consumo é a harmonização dos interesses, de modo que as normas que regulam a matéria devem reconhecer o desequilíbrio apriorístico entre as partes contratantes, porém, sem fomentar a aniquilação do fornecedor de bens e serviços. A tutela do consumidor deve estar atenta à análise econômica do direito, de modo a não ensejar que a outorga de demasiados e irrefletidos benefícios em prol do vulnerável acabasse por onerar o outro contratante que, invariavelmente, devolveria os custos da operação ao player fraco do negócio.

Se é verdade que o Direito do Consumidor serve para refrear os ímpetos do mercado sobre o consumidor, não menos correto é que a regulação linear consumidor-fornecedor, "não se trata de normas que limitam ou restrinjam o consumo." ${ }^{33}$

No processo de reforma de atualização do CDC, iniciado em 2010 no Senado Federal, foram discutidos três projetos de lei que objetivam a inclusão do princípio do consumo sustentável, do direito à informação ambiental e de outras iniciativas aptas a salvaguardar o consumidor de mecanismos utilizados pelo mercado para induzir ao consumo. Durante as discussões naquela casa legislativa, havia-se previsto a inclusão de dispositivo que traduzia esse objetivo, o qual idealizava a exigência de indicação expressa de informação sobre a vida útil dos produtos e serviços, entretanto, esse dispositivo acabou por ser retirado do relatório final do senador Ricardo Ferraço ${ }^{34}$. Após aprovação do relatório final no Senado, o projeto de lei seguiu para a Câmara Federal.

Proteger o consumidor significa, por via direta, reafirmar a continuidade do consumo enquanto elemento central da sociedade, o que se pode constatar em vários dispositivos do CDC, mas que tem especial transparência em seu artigo 4으, inciso IV, quanto à tutela da educação e informação para o consumo.

O conteúdo do princípio a educação para o consumo deve incorporar a proteção ao meio ambiente e a utilização eficiente de materiais, a partir do sistema de proteção do consumidor, com a ampla utilização da informação como instrumento de enfrentamento às estratégias do mercado para indução ao consumo, realizando, assim, no plano infraconstitucional, a previsão constitucional de defesa do consumidor e proteção ao meio ambiente enquanto direitos fundamentais. 
Inserindo-se a Constituição Federal de 1988 (CF/88) como o guia valorativo de todas as ações do Estado e da sociedade, cumpre lembrar que figura como ao cidadão o direito fundamental ao "meio ambiente ecologicamente equilibrado" (art. 225). O figurino constitucional modula a ação estatal, o que para alguns autores institui a passagem de um Estado de Direito para um Estado de Direito Ambiental. Essa construção político-normativa representa uma resposta aos problemas advindos da crise ecológica produzida pela sociedade de risco (didático lembrar que o acidente nuclear na cidade de Pripyat deixou um legado indelével no tratamento das questões ambientais que lhe são posteriores).

Trata-se de uma transformação na estrutura do Estado para a incorporação, em todos os níveis, de valores ecológicos, promovendo-se a implantação de aparatos jurídicos e sociais capazes de assegurar a higidez do meio ambiente como fator indispensável à sadia qualidade de vida. Por conseguinte, o consumo sustentável mostra-se como desdobramento do direito fundamental ao meio ambiente e, por isso mesmo, detém semelhante natureza enquanto direito fundamental. O direito à informação ambiental, portanto, revela-se como garantia essencial para a efetividade do direito ao consumo sustentável.

\title{
4 O Direito à Informação Ambiental enquanto Garantia de Efetividade do Direito Fundamental ao Consumo Sustentável
}

Nesta pesquisa, a conexão entre o consumo e as questões ambientais foi tomada a partir do pressuposto que a existência de um direito fundamental ao meio ambiente saudável implica no reconhecimento de um direito fundamental do consumidor ao consumo sustentável.

As Diretrizes das Nações Unidas para a Proteção do Consumidor inicialmente não faziam alusão ao princípio do consumo sustentável. Em 26 de julho de 1999, como resultado do impacto das discussões da ECO-92, significativa deliberação resolveu incorporar essa pauta, nos seguintes termos:

\begin{abstract}
Consumo sustentável inclui atender as necessidades de bens e serviços das gerações presentes e futuras de modo tal que sejam sustentáveis do ponto de vista econômico, social e ambiental". A responsabilidade pelo consumo sustentável é compartilhada entre todos os membros e organizações da sociedade, incluídos os consumidores informados, governos, empresas, organizações laborais, consumeristas e ambientais, que desempenham funções particularmente importantes. Os consumidores informados têm uma função essencial na promoção do consumo que é sustentável do ponto de vista ambiental, econômico e social, inclusive pelos efeitos de suas escolhas sobre os produtores. Os governos devem promover 0 desenvolvimento e a implementação de políticas para o consumo sustentável e a integração dessas políticas com outras políticas públicas. ${ }^{35}$
\end{abstract}

A ideia do consumo sustentável inclui uma responsabilidade com as gerações futuras, sendo a responsabilidade por um consumo sustentável de toda a sociedade. O envolvimento com as questões ambientais por parte dos arautos do desenvolvimento econômico promoveu uma reconfiguração ecológica compatível com os negócios de mercado.

Na opinião de Vittorio Hösle, três fatores contribuíram para tal aderência de variados segmentos societários no intuito de enfrentar os desafios da crise ecológica: a) motivos existenciais éticos decorrentes dos meios de massa ("as perguntas críticas das próprias crianças não podem ser evadidas"); b) harmonia entre os valores corporativos de uma empresa e os valores da sociedade em geral, com o propósito de manter o envolvimento das pessoas no

70 | Revista Brasileira de Direito Animal, e-issn: 2317-4552, Salvador, volume 15, n. 01, p.61-75, Jan-Abril 2020 
projeto de identificação da empresa; c) satisfação dos consumidores em relação à imagem da empresa. $^{36}$

Desta forma, a promoção do consumo sustentável passa indiscutivelmente pela garantia de prestação de informação ambiental ao consumidor. Essa noção de ciclo de vida de um produto foi traduzida em normas técnicas uniformizadoras, a nível internacional, pela International Standardization Organization - ISO. A norma de qualidade ISO 14040, dentre outras, regula a análise do ciclo de vida de um produto, utilizando uma metodologia que permite avaliar os potenciais impactos sobre o meio ambiente de um produto ou serviço desde a extração dos recursos necessários para sua elaboração. ${ }^{37}$

No Brasil, as certificações e a normalização técnica são veiculadas pela Associação Brasileira de Normas Técnicas (ABNT), que classificam as informações e uniformizam a rotulagem ambiental, entretanto, importante que se registre que "essas normas não são obrigatórias, até porque emanam de uma entidade privada, salvo se alguma lei ou contrato fizer-lhe remissão expressa." Em 7 de março de 2016, o Instituto Nacional de Meteorologia, Qualidade e Tecnologia (INMETRO) expediu a Portaria no 100/2016 que aprova os requisitos gerais do programa de rotulagem ambiental (adotando os parâmetros utilizados pelas normas ISO 14000). ${ }^{38}$

Analisando as normas da ABNT concernentes ao selo ISO 14000, tem-se que inicialmente se estabeleceram "os princípios e procedimentos para o desenvolvimento de programas de rotulagem ambiental, incluindo a seleção de categorias de produtos, critérios ambientais e características funcionais dos produtos, bem como para avaliar e demonstrar sua conformidade" (NBR ISO 14024:2010). Dando sequência ao aprimoramento técnico das normas consumeristas voltadas a preservação do meio ambiente, nova orientação foi editada especificando "os requisitos para autodeclarações ambientais, incluindo textos, símbolos e gráficos, no que se refere aos produtos; descrevendo termos selecionados usados comumente em declarações ambientais e fornecendo qualificações para seu uso" (NBR ISO 14021:2013). Por fim, uma derradeira regulamentação sobre o tema definiu "que esta rotulagem é a que utiliza as informações referentes a todos os aspectos ambientais do produto ou serviço em todas as suas etapas de produção e consumo, abarcando seu ciclo de vida completo e cada um dos seus componentes" (NBR ISO 14025:2015).

Verifica-se que a rotulagem ambiental (elemento indissociável do direito fundamental à informação - previsto no art. 5ㅇ, XIV, da CF/88, reiteradamente tratado no presente artigo) amplia a prática consciente no ato da aquisição de um produto ou contratação de um serviço, pela perspectiva ecológica que seria disponibilizada ao consumidor. O art. 6 o do CDC assegura a informação adequada e clara ao consumidor sobre os diferentes produtos e serviços, com especificação correta de quantidade, características, composição, qualidade e preço, bem como os riscos que apresentem, incorporando o princípio da precaução (próprio do direito ambiental). ${ }^{39}$

Ressalte-se que os incisos II e III, do art. 6ㅇ, do CDC, têm como objetivo garantir a autodeterminação do consumidor pela proteção de sua liberdade de escolha, no sentido de manter a capacidade de realização de uma opção informada. Pautados nos princípios da transparência e da boa-fé objetiva, inspiram a confiança no consumidor sobre a qualidade e as características do bem adquirido, o que tem raiz constitucional no art. 5ํ, XIV, da CF/88.

Registre-se, no entanto, que esse rol de informações não é suficiente para neutralizar os impulsos consumistas e não sustentáveis fomentados pelo mercado. Indispensável o conhecimento sobre os impactos ao meio ambiente com a produção do bem e com a sua posterior destinação. A compra consciente e responsável se inicia com a prévia avaliação do consumidor sobre as consequências de seu ato de consumo, a partir do conhecimento sobre as consequências de sua aquisição para o meio ambiente.

71 | Revista Brasileira de Direito Animal, e-issn: 2317-4552, Salvador, volume 15, n. 01, p.61-75, Jan-Abril 2020 
$\mathrm{Na}$ via constitucional do Estado de Direito Ambiental, o acesso ao conhecimento sobre o produto, na perspectiva ecológica, desde o primeiro momento de aproximação do consumidor com o bem ou serviço oferecido, garante que o ato de aquisição se realize dentro de um maior espaço de consciência sobre o nível de sustentabilidade do consumo.

A garantia da informação significa, de um lado, o empoderamento do consumidor pela reafirmação de sua autodeterminação frente ao mercado, mas, de outro lado, significa o compartilhamento substancial da responsabilidade entre consumidor e fornecedor na relação consumerista. O consumidor abandona a passividade e passa a atuar de modo pró-ativo na seleção de produtos e bens de serviço mais sustentáveis o que, por uma visão circular, passa a exigir do mercado o oferecimento de produtos e bens de serviço comprometidos com a sustentabilidade.

Esse círculo virtuoso acabaria por criar uma demanda pela qualidade ambiental dos produtos ou serviços e pela prevenção de resíduos. Por isso mesmo, entende-se que o direito à informação ambiental representa ferramenta que instrumentaliza a efetividade ao direito fundamental do consumidor ao consumo sustentável.

O surgimento das ecomarcas é um fenômeno que comprova como o mercado muda seu hábito de produção e ofertas diante de um público voltado a um novo ethos (como já se anunciou, através da mudança do "homo consumericus" para o ser bioético), o que reafirma que essa mudança cultural pode ser construída com a afirmação do direito à informação, como ferramenta de educação ambiental e de estímulo ao consumo consciente.

Comentando a sugestão de introduzir essa exigência no CDC, Garcia assevera que "a informação do tempo de vida útil dos produtos e serviços seria ferramenta importante na promoção do consumo sustentável e deriva do direito à informação ambiental." ${ }^{40}$ Segundo Miragem, a exigência desse tipo de informação sobre os produtos naturais duráveis representa um desafio, pois a introdução de novos dados e informações vinculadas a os impactos ambientais dos produtos não devem deixar de lado as já exigidas legalmente, e mesmo assim devem ser compreensíveis para os consumidores, evitando uma inflação informativa, "de modo que sejam compreensíveis aos consumidores a que se destinam, observado do tríduo critério tempo $\mathrm{x}$ conteúdo x modo de divulgação que orienta o cumprimento do dever de informar" ${ }^{41}$

Há de se ponderar, entretanto, que os supostos malefícios do excesso de informação (alegado por alguns autores) não deve comprometer a relevância da conscientização ora proposta, já que a informação ambiental sobre o produto pode ser instrumentalizada por viáveis instrumentos tecnológicos com vistas a evitar a possível inflação informativa no rótulo dos produtos (o uso de $Q R$ Codes, por exemplo). Se a criatividade é o cerne da publicidade, que o seja também para a reformulação das formas de informação ao consumidor.

De outro lado, caso as alterações legislativas sejam implementadas, conforme relatório final produzido no Senado Federal, com a inclusão do princípio do consumo sustentável, ainda que tardiamente, as regras que regulam a obrigação genérica de informar devem ser interpretadas e integradas o novo princípio que, nada mais representa do que a fiel adequação do $\mathrm{CDC}$ aos preceitos constitucionais sobre consumo e meio ambiente.

Lúcido e pragmático o argumento de Vittorio Hösle quando anuncia a necessidade de mudança dos agentes do mercado (sobretudo os dirigentes de empresas privadas) em relação ao enfrentamento da crise ecológica contemporânea, sobretudo em sua compreensão acerca da noção de progresso irrefletido, olvidando da valorização da dimensão humana. Para o autor, o empresário do século XXI "levará a mal o pensamento puramente quantitativo. A ele, a medida (a quantidade que se eleva a qualidade) será mais importante que o sempre-mais; ele também rejeitará, então, a destruição de dimensões humanas, quando ela promete o lucro" ${ }^{4}{ }^{2}$ 


\section{Conclusão}

A função social do contrato não fulmina os princípios clássicos do direito privado como a autonomia da vontade, a intangibilidade do conteúdo do acordo ou a eficácia de seus efeitos. Ao contrário, diante de uma teoria contratual contemporânea hipercomplexa, todos esses valores se complementam. A ordem constitucional, na qualidade de sistema harmônico, estabelece, na área econômica, a convivência de institutos para a defesa do consumidor e do meio ambiente, sendo, portanto, o princípio da sustentabilidade comum aos subsistemas jurídicos consumerista e ambiental.

A ampliação da conscientização do consumidor (em uma perspectiva ecológica do ato de consumir) passa pela integração do princípio do consumo sustentável em atenção aos valores instituídos na CF/88. A informação ambiental obrigatória materializaria a proteção contra a publicidade enganosa e abusiva, assegurando transparência e lealdade nas relações de consumo. Prestar informação sinaliza objetivamente o princípio da boa-fé, por vincular o fornecedor aos dados indicados.

Referido princípio permite argumentar a ampliação do conteúdo da obrigação de informar dos provedores, exigindo a inclusão (no caso dos produtos de natureza durável) da informação sobre a duração da vida dos mesmos, porquanto se trata de uma característica relevante para que o consumidor realize sua opção por um consumo sustentável, podendo incorporar em sua decisão a consideração de outras variáveis para além da simples análise sobre o preço do produto ou serviço.

A afirmação do direito à informação ambiental do consumidor revela-se importante instrumento para reconstrução da autonomia do consumidor na medida em que a decisão pela aquisição de um produto ou serviço poderá ser determinada pela sua avaliação ambiental. Além disso, a publicidade também é passível de condicionar comportamento dos consumidores, razão pela qual o CDC coíbe a publicidade que incite práticas que violem valores morais, culturais, sociais e ambientais, tida como publicidade abusiva.

A consolidação dessa política pública nas relações de consumo teria o condão de ser eficaz para o combate da obsolescência programa, do greenwashing e da publicidade mistificadora, qualificando-se como social e juridicamente enriquecedora se a alteração legislativa do CDC (cujo projeto tramita perante a Câmara dos Deputados) resgatasse a exigência de prestação de informação ambiental.

Com efeito, em face do enraizamento das estratégias do mercado, a construção de uma cultura consumerista consciente dos riscos produzidos pelo consumo consiste em processo histórico complexo que exigirá das várias instituições posições explícitas de enfrentamento das táticas mercadológicas. Informação gera conhecimento que, por sua vez, gera inegavelmente o poder de neutralizar a interferência das estratégias de mercado sobre o consumidor e, assim, fomentar práticas de consumo sustentável.

\section{Notas de referência}

\footnotetext{
${ }^{1}$ THALER, Richard H. Nudge: como tomar melhores decisões sobre saúde, dinheiro e felicidade (tradução Angelo Lessa), $1^{\mathrm{a}}$ edição, Rio de Janeiro: Objetiva, 2019, p. 201.

${ }^{2}$ BECK, Ulrich. Sociedade de risco: rumo a uma outra modernidade. Tradução de Sebastião Nascimento. 2. ed. São Paulo: Editora 34, 2011, p. 48.

${ }_{3}^{3}$ BAUMAN, Zygmunt. Vida para Consumo: a transformação das pessoas em mercadorias. Tradução Carlos Alberto Medeiros. Rio de Janeiro: Jorge Zahar Ed., 2008.
}

73 | Revista Brasileira de Direito Animal, e-issn: 2317-4552, Salvador, volume 15, n. 01, p.61-75, Jan-Abril 2020 
${ }^{4}$ BAUMAN, Zygmunt. Vida para Consumo: a transformação das pessoas em mercadorias. Tradução Carlos Alberto Medeiros. Rio de Janeiro: Jorge Zahar Ed., 2008 p. 34.

${ }^{5}$ RIBEIRO, Alfredo Rangel. Consumo helicoidal: da tutela para o consumo à proteção em face do consumo. Tese (doutorado) - Centro de Ciências Jurídicas, Universidade Federal da Paraíba. João Pessoa: 2016.

${ }^{6}$ LIPOVETSKY, G. A felicidade paradoxal: ENSAIO SOBRE A SOCIEDADE DE HIPERCONSUMO, São Paulo: Companhia das Letras, 2007, p. 399.

${ }^{7}$ BAUMAN, 2008, op. cit., p. 41

${ }^{8}$ RIBEIRO, Alfredo Rangel. Consumo helicoidal: da tutela para o consumo à proteção em face do consumo. Tese (doutorado) - Centro de Ciências Jurídicas, Universidade Federal da Paraíba. João Pessoa: 2016, p. 114.

${ }^{9}$ DEBORD, GUY. A Sociedade do Espetáculo. Rio de Janeiro: Contraponto, 1997, p. 125.

${ }^{10}$ LIPOVETSKY, G. O império do efêmero. São Paulo: Companhia das Letras, 1989, p.69.

${ }^{11}$ BAUMAN, 2008, op. cit., p. 96.

${ }^{12}$ HARVEY, D. Condição pós-moderna: uma pesquisa sobre as origens da mudança cultural. São Paulo: Loyola, 1998

${ }^{13}$ HÖSLE, Vittorio. Filosofia da crise ecológica: conferências moscovitas. São Paulo: Editoria LiberArs, 2019, p. $14-15$

${ }^{14}$ PASQUALOTTO, Adalberto e SOARES, Rampazzo Flaviana. Consumidor hipervulnerável: análise crítica, substrato axiológico, contornos e abrangência. Revista de Direito do Consumidor, vol. 113, ano 26, p. 81-100. São Paulo: RT, set/out, 2017, p. 100.

${ }^{15}$ MORAES, Paulo Valério Dal Pai. Macrorrelação ambiental de consumo: responsabilidade pós-consumo ou relação coletiva de consumo. Porto Alegre: Livraria do Advogado, 2013, p. 237.

${ }^{16}$ LATOUCHE, S. Bon pour la casse: Les déraisons de l'obsolescence programmée. Les Liens qui Liberent, Paris, 2012.

17 HOLANDA, Fábio Campelo Conrado de. Indução de comportamentos (neurolaw): obsolescência programada na sociedade pós-moderna e uma reflexão sobre as relações de consumo. Revista Argumentum, Marília/SP, V. 19, N. 1, pp. 111-127, Jan.-Abr. 2018.

${ }^{18}$ LATOUCHE, Serge. O pequeno tratado do decrescimento sereno. reimp. Lisboa: Edições 70, 2012, p. 17.

${ }^{19}$ RIBEIRO, Alfredo Rangel. Consumo helicoidal: da tutela para o consumo à proteção em face do consumo. Tese (doutorado) - Centro de Ciências Jurídicas, Universidade Federal da Paraíba. João Pessoa: 2016, p.106.

${ }^{20}$ LORENZETTI, Pablo. Re-explorando los vínculos entre consumo y ambiente a partir del paradigma ecocéntrico. In MARQUES, Claudia Lima (Org.). Revista de Direito do Consumidor. Revista dos Tribunais São Paulo, p. 357-358.

${ }^{21}$ O primeiro a empregar o termo Bioética foi Van Rensselaer Potter21, em 1970, no artigo "Bioethics, the science of survival", uma adaptação do capítulo I do livro "Bioethics: bridge to the future", que estava no prelo.

22 JONAS, Hans. El principio de responsabilidad. Ensayo de una ética para la civilización tecnológica. Traducción de Javier Maria Fernández Retenaga. Barcelona: Editorial Herder, 1995, p. 359.

${ }^{23}$ HÖSLE, Vittorio. Filosofia da crise ecológica: conferências moscovitas. São Paulo: Editoria LiberArs, 2019, p. $75-97$.

${ }^{24}$ HÖSLE, Vittorio. Filosofia da crise ecológica: conferências moscovitas. São Paulo: Editoria LiberArs, 2019, p. 99-111.

${ }^{25}$ DEBORD, GUY. A Sociedade do Espetáculo. Rio de Janeiro: Contraponto, 1997, p. 28.

${ }^{26}$ NORAT, Markus Samuel Leite; ALMEIDA, Ithanyê Heloísa Arcoverde. Obsolescência programada e consumo sustentável. João Pessoa: Markus Samuel Leite Norat, 2019, p. 94-95.

${ }^{27}$ Ibidem, p. 95.

${ }^{28}$ BARIFOUSE, Leonardo. O controle jurídico da publicidade na trincheira do consumismo. Revista de Direito do Consumidor, vol. 116, ano 27, p.95-125. São Paulo. Ed. RT, mar-abr, 2018, p. 111.

${ }^{29}$ Lane, Eric L. Consumer Protection in the Eco-Mark Era: A Preliminary Survey andAssessment of AntiGreenwashing Activity and Eco-Mark Enforcement. John Marshall Review of Intellectual Property Law, vol. 9, no. 3, 2010, p. [i]-773. HeinOnline. Acesso em 22 de nov. 2019.

30 MACHADO, R.; SCHNEIDER, P. H. O Greenwashing e os direitos fundamentais na sociedade da informação: desafios para uma regulação eficiente. Prisma Jurídico, São Paulo, v. 14, n. 1, p. 207-226, jan./jun. 2015.

${ }^{31}$ PASQUALOTTO, Adalberto e SOARES, Rampazzo Flaviana. Consumidor hipervulnerável: análise crítica, substrato axiológico, contornos e abrangência. Revista de Direito do Consumidor, vol. 113, ano 26, p. 81-100. São Paulo: RT, set/out, 2017, p. 97.

32 BARIFOUSE, Leonardo. O controle jurídico da publicidade na trincheira do consumismo. Revista de Direito do Consumidor, vol. 116, ano 27, p.95-125. São Paulo. Ed. RT, mar-abr, 2018, p. 109. 
${ }^{33}$ RIBEIRO, Alfredo Rangel. Consumo helicoidal: da tutela para o consumo à proteção em face do consumo. Tese (doutorado) - Centro de Ciências Jurídicas, Universidade Federal da Paraíba. João Pessoa: 2016, p. 111.

${ }^{34}$ GARCIA, Leonardo de Medeiros. Consumo sustentável: a proteção do meio ambiente no Código de Defesa do Consumidor. Salvador: JusPODIVM, 2016, p. 147.

${ }^{35}$ UNITED NATIONS. United Nations guidelines on consumer protection: as expanded in 1999. Genebra: UNCTAD, 2011, p. 11, tradução livre. Disponível em: Acesso em: 24 nov 2019.

${ }^{36}$ HÖSLE, Vittorio. Filosofia da crise ecológica: conferências moscovitas. São Paulo: Editoria LiberArs, 2019, p. 111-112.

${ }^{37}$ International Organization for Standardization. ISO 14040: Gestão ambiental - Avaliação do ciclo de vida Princípios e estrutura. Disponível em: https://www.iso.org/standard/37456.html. Acesso em 02 de dezembro de 2019.

38 Brasil. Secretaria Nacional do Consumidor. Departamento de Proteção e Defesa do Consumidor. Consumo sustentável / Departamento de Proteção e Defesa do Consumidor; Patrícia Faga Iglecias Lemos [et al]; coordenação de Patrícia Faga Iglecias Lemos, Juliana Pereira da Silva e Amaury Martins Oliva. -- Brasília: Ministério da Justiça, 2013, p. 130.

${ }^{39}$ GARCIA, Leonardo de Medeiros. Consumo sustentável: a proteção do meio ambiente no Código de Defesa do Consumidor. Salvador: JusPODIVM, 2016, p. 146.

${ }^{40}$ GARCIA, Leonardo de Medeiros. Consumo sustentável: a proteção do meio ambiente no Código de Defesa do Consumidor. Salvador: JusPODIVM, 2016, p. 147.

41 MIRAGEM, Bruno. CONSUMO SUSTENTÁVEL E DESENVOLVIMENTO: POR UMA AGENDA COMUM DO DIREITO DO CONSUMIDOR E DO DIREITO AMBIENTAL. Revista do Ministério Público do Rio Grande do Sul, Porto Alegre, n. 74, jul. 2013 - dez. 2013, p. 237.

42 HÖSLE, Vittorio. Filosofia da crise ecológica: conferências moscovitas. São Paulo: Editoria LiberArs, 2019, p. 115. 